\title{
Rancang Bangun Sensor Jarak sebagai Alat Bantu Memarkir Mobil berbasis Mikrokontroler Arduino Uno
}

\author{
Pedro Paulo de Jesus Costa Henriques ${ }^{1}$, I. G. A. P. Raka Agung ${ }^{2}$, Lie Jasa ${ }^{3}$
}

\begin{abstract}
Cars are a transportation mode that is widely used in society. Every year in Indonesia and other countries experience a continuous increase in the number of cars. The intensity of cars especially in parking areas often become a challenge for drivers to park cars and increases the risk of a crash. This research aims to design and build a distance sensor device that helps to park cars based on Arduino Uno microcontroller which is hoped to help decrease the risk of cars crashing to another car or object. This device will will produce three types of input that will inform the driver on the distance detected, between the car and another object. The first output is in text form displayed on an LCD screen, then the second output is a buzz produced by a buzzer and the third output is produced by a speaker which produces sound of audio recordings voicing the distance detected by the sensor.
\end{abstract}

Intisari - Mobil merupakan moda transportasi yang paling banyak digunakan masyakat. Setiap tahun Indonesia maupun negara lainnya terus mengalami peningkatan dalam jumlah mobil. Padatnya mobil khususnya di lahan parkir sering menjadi tantangan bagi pengendara mobil saat memarkir mobil dan hal ini meningkatkan resiko tabrakan. Penelitian ini bertujuan untuk merancang dan membangun sensor jarak sebagai alat bantu memarkir mobil berbasis Mikrokontroler Arduino Uno, yang diharapkan dapat membantu mengurangi resiko tabrakan antara mobil dengan mobil lain ataupun benda lain. Alat yang dibangun ini akan menghasilkan tiga macam output yang akan menginformasikan pengemudi tentang jarak antara mobil dengan benda lain yang dideteksi. Output pertama melalui layar LCD berupa tulisan, kemudian output kedua melalui dengingan buzzer dan output ketiga melalui speaker yang menghasilkan audio rekaman menyuarakan jarak yang terdeteksi oleh sensor.

Kata Kunci- sensor jarak, mikrontroler, buzzer, speaker, LCD

\section{PENDAHULUAN}

Mobil merupakan moda transportasi yang paling banyak digunakan masyarakat. Dengan meningkatnya jumlah penduduk di suatu daerah, maka kebutuhan transportasi pun semakin meningkat. Peningkatan tersebut turut membuat kecelakaan mobil menjadi lebih rawan pada saat memarkir. Kecelakaan seperti ini dapat dihindari apabila mobil tersebut dibantu dengan sensor jarak ultrasonik.

${ }^{1}$ Mahasiswa, Teknik Elektro dan Komputer Fakultas Teknik Universitas Udayana, Jln. Tukad Badung XIIIA No4 panjer Denpasar Selatan 80221. INDONESIA (telp:082144434711;e-mail: necohenriques15@gmail.com)

${ }^{2}$ Dosen, Program Studi Teknik Elektro dan Komputer Fakultas Teknik Universitas Udayana, Br. Anggarkasih, Medahan, Blahbatuh Gianyar 80581 INDONESIA (telp:08999898301; e-mail: igapraka@yahoo.co.id).

${ }^{3}$ Dosen, Program Studi Teknik Elektro dan Komputer Fakultas Teknik Universitas Udayana, Jln. Gunung Merapi No22, Denpasar, Bali 80119 INDONESIA(telp: 08123931535;e-mail: liejasa@unud.ac.id)
Sensor jarak ultrasonik merupakan sebuah alat yang mendeteksi jarak antara sensor dengan benda-benda yang ada di depannya. Sensor jarak ultrasonik membantu pengemudi mengetahui jarak mobil dengan benda dibelakangnya. Dengan demikian dapat membantu mencegah terjadi tabrakan antara mobil dengan benda atau mobil lainnya.

Pada penelitian sebelumnya telah dibuat suatu sistem rekayasa pengamanan parkir kendaraan roda empat transmisi otomatis menggunakan sensor ultrasonik yang dikendalikan oleh mikrontroler Arduino Uno. Alat tersebut mencegah mobil menabrak benda lain dengan cara mematikan keseluruhan kelistrikan kendaraan dan mengunci roda kendaraan sehingga kendaraan berhenti bergerak[1]. Sama halnya dengan penelitian tersebut, penelitian ini juga menggunakan mikrontroler Arduino Uno sebagai pengendali buzzer dan LCD untuk output. Akan tetapi, penelitian tersebut tidak menggunakan MP3 Shield Player dan speaker. Alat yang dibuat dalam penelitian ini dapat memberikan informasi jarak yang terdeteksi tidak hanya melalui tulisan di LCD saja atau melalui dengingan buzzer, akan tetapi melalui audio yang disuarakan oleh speaker sehingga pengemudi tidak diharuskan menatap LCD untuk mengetahui jarak.

\section{TINJAUAN PUSTAKA}

Dalam tinjauan pustaka, berikut ini komponen-komponen yang digunakan dalam perancangan rangkaian alat bantu mamarkir mobil berbasis mikrokontroler Arduino Uno.

\section{A. Sensor Ultrasonik HC-SR04}

Sensor ultrasonik HC-SR04 merupakan sensor yang dapat mendeteksi jarak obyek dengan memancarkan gelombang ultrasonik dengan frekuensi $40 \mathrm{KHz}$ dan kemudian mendeteksi pantulannya[2]. Bentuk fisik dari sensor ultrasonik dapat dilihat pada gambar 1 .

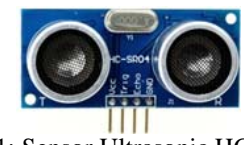

Gambar 1: Sensor Ultrasonic HC-SR04[2]

Sensor ultrasonik memiliki empat pin dua pin diantaranya sebagai pemancar (Trigger) dan penerima (Echo), dan dua pin sebagai sumber tegangan. Sensor ultrasonik dapat mendeteksi jarak dari $2 \mathrm{~cm}$ hingga $400 \mathrm{~cm}$ dengan akurasi $0,3 \mathrm{~cm}[2]$.

B. Arduino UNO R3

Arduino Uno R3 adalah salah satu kit mikrokontroler berbasis Atmega328. Penggunaan Arduino Uno R3 lebih memudahan penggunanya untuk membuat berbagai hal yang berkaitan dengan mikrokontroler, karena di dalamnya sudah tersedia yang dibutuhkan oleh mikrokontroler[3]. Salah satu kelebihan dari arduino Uno ini adalah didukung oleh opensource software Arduino IDE (Integrated Development Enviroment) untuk melakukan penulisan program[4]. Data 
Majalah Ilmiah Teknologi Elektro, Vol. 17, No. 1,Januari -April 2018

DOI: https://doi.org/10.24843/MITE.2018.v17i01.P10

masukan dari sensor ultrasonik melalui ping Digital akan diproses oleh arduino kemudian dikirimkan ke LCD, Buzzer, dan Speaker sebagai output .

\section{Mp3 Player Shield}

Mp3 Player Shield merupakan sebuah audio codec IC berbasis chip VS1053B dan memiliki bentuk menyerupai arduino uno. Mp3 Player Shield berfungsi sebagai decoder Mp3 yang dapat menyimpan musik maupun efek-efek suara pada kartu penyimpanan micro SD dan menghasilkan efek suara lewat ouput headset ataupun speaker. Chip VS1053B ini mampu mendekode file Ogg Vorbis/ MP3/ AAC/ WMA/ MIDI dan encoding IMA ADPCM. VS1053 menerima input beatstream melalui serial input bus (SPI). Setelah suara didekode oleh IC, audionya dapat di dengar melalui headphone 3.5mm dan juga 2-pin 0.1" pitch header untuk speaker[5]. Mp3 Player Shield memiliki pin-pin eksklusif yang hanya dapat dihubungkan pada perangkat tertentu saja. Pin-pin eksklusif tersebut antara lain:

1. D2 terhubung pada output VS1053B bagian data request (permintaan data). Pin ini berfungsi untuk memberitahukan Arduino bahwa bagian IC memerlukan data musik.

2. D6 terhubung pada input VS1053B bagian chip select. Pin ini berfungsi untuk memberitahukan chip saat data sedang dikirim.

3. D7 terhubung pada input VS1053B bagian data chip select, yang memberitahukan chip saat data music sedang dikirim.

4. D8 terhubung pada input VS1053B bagian reset.

5. D9 terhubung ke input kartu MicroSD bagian chip select D11, D12, dan D13 dapat digunakan dengan komponenkomponen SPI lainnya akan tetapi tidak dapat digunakan dengan komponen selain SPI. Ada beberapa pin yang bebas untuk dihubungkan dengan komponen-komponen lain, antara lain:

1. Pin-pin UART - RX and $\mathbf{T X}-$ on pins 0 and 1

2. D5 and D10 (PWM pins!)

3. Pin-pin analog (A0-A5)

Bentuk fisik dan konfigurasi pin Mp3 Player Shield dapat dilihat pada gambar 2 .

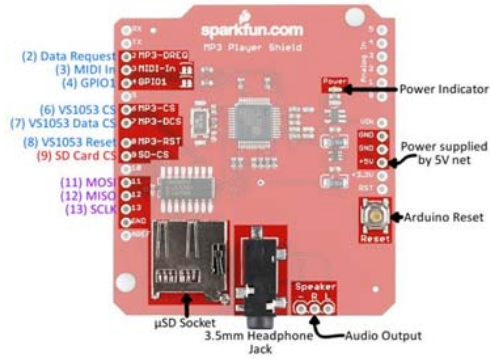

Gambar 2: Bentuk fisik dan konfigurasi pin Mp3 Player Shield

\section{Speaker}

Speaker atau dalam bahasa Indonesia, pengeras suara, merupakan perangkat keras output yang berfungsi untuk menghasilkan suara. Speaker adalah transduser yang dapat mengubah sinyal listrik menjadi frekuensi audio (sinyal suara) yang dapat didengar oleh telinga manusia dengan cara mengetarkan komponen energy pada speaker tersebut sehingga terjadilah gelombang suara. Yang dimaksud dengan Pedro Paulo De J C Henriques: Rancang Bangun Sensor Jarak ...... "suara" sebenarnya adalah frekuensi yang dapat didengar oleh telinga manusia yaitu frekuensi yang berkisar di antara $20 \mathrm{~Hz}-$ $20.000 \mathrm{~Hz}[6]$.

\section{E. Buzzer}

Buzzer adalah sebuah komponen elektronika yang berfungsi untuk mengubah getaran listrik menjadi getaran suara. Pada dasarnya prinsip kerja buzzer hamper sama dengan loud speaker, jadi buzzer juga terdiri dari kumparan yang terpasang pada diafragma dan kemudian kumparan tersebut dialiri arus sehingga menjadi energi magnet, kumparan tadi akan tertarik ke dalam atau keluar, tergantung dari arah arus dan polaritas magnetnya, karena kumparan dipasang pada diafragma maka setiap gerakan kumparan akan menggerakkan diafragma secara bolak-balik sehingga membuat udara bergetar yang akan menghasilkan suara[7].

\section{F. LCD (Liquid Crystal Display)}

Liquid Crystal Display (LCD) merupakan sebuah teknologi layar digital yang menghasilkan citra pada sebuah permukaan yang rata (flat) dengan energi sinar pada energi cair dan filter berwarna, yang mempunyai struktur molekul polar, dilapis antara dua elektroda yang transparan[8]. Bila medan listrik diberikan, molekul menyesuaikan posisinya pada medan, membentuk susunan kristalin yang mempolarisasi cahaya yang melaluinya.

LCD berfungsi menampilkan suatu nilai hasil sensor, menampilkan teks, atau menampilkan menu pada aplikasi mikrokontroler. LCD yang digunakan pada penelitian ini adalah jenis LCD M1632. LCD M1632 merupakan modul LCD dengan tampilan $16 \mathrm{~cm} \times 2 \mathrm{~cm}$ baris dengan konsumsi daya rendah sehingga efisien dalam konsumsi energi[8].

\section{PERANCANGAN SISTEM}

Dalam perancagan sistem dapat dijelaskan sebagai berikut:

\section{A. Perancangan Hardware (Perangkat Keras)}

Perancangan Hardware pada sensor jarak sebagai alat bantu memmarkir mobil berbasis mikrokontroler arduino uno menggunakan program Fritzing 0.9.2.

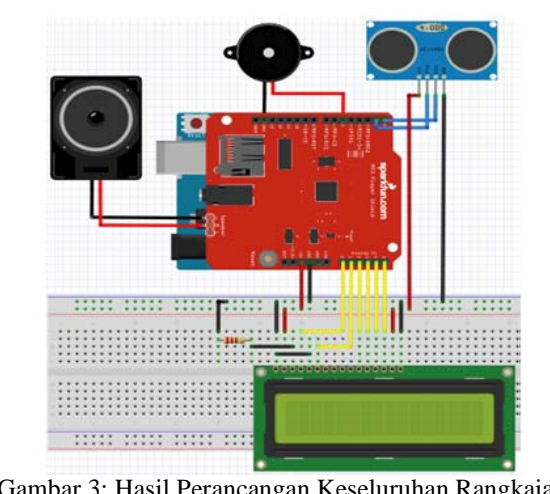

Hubungan pin Arduino Uno R3 dengan I/O alat sensor jarak dapat dilihat pada tabel 1.

TABEL I

HUBUNGAN PIN ARDUINO UNO R3 DENGAN I/O

p-ISSN:1693 - 2951; e-ISSN: 2503-2372 


\begin{tabular}{|c|c|c|c|c|}
\hline $\begin{array}{c}\text { Pin } \\
\text { Arduino }\end{array}$ & $\begin{array}{c}\text { Pin Sensor } \\
\text { Ultrasonik }\end{array}$ & $\begin{array}{c}\text { Pin Mp3 } \\
\text { Player Shield }\end{array}$ & $\begin{array}{c}\text { Pin LCD (no } \\
\text { pin) }\end{array}$ & $\begin{array}{c}\text { Pin } \\
\text { Buzzer }\end{array}$ \\
\hline O (RX) & ECHO & - & - & - \\
\hline $1($ TX) & TRIGGER & - & - & - \\
\hline 2 & - & 2 (DREQ) & - & - \\
\hline 3 & - & 3 (MIDI IN) & - & - \\
\hline 4 & - & $4($ GPI01) & - & - \\
\hline 5 & - & - & - & POSITIF \\
\hline 6 & - & $6(\mathrm{CS})$ & - & - \\
\hline 7 & - & $7(\mathrm{DCS})$ & - & - \\
\hline 8 & - & $8(\mathrm{RST})$ & - & - \\
\hline 9 & - & 9 (SD-CS) & - & - \\
\hline 10 & - & - & - & - \\
\hline 11 & - & $11(\mathrm{MOSI})$ & - & - \\
\hline 12 & - & $12(\mathrm{MOSI})$ & - & - \\
\hline 13 & - & $13(\mathrm{SCLK})$ & - & - \\
\hline AREF & - & - & - & - \\
\hline A0 & - & - & RS(4) & - \\
\hline A1 & - & - & E(6) & - \\
\hline A2 & - & - & D4(11) & - \\
\hline A3 & - & - & D5(12) & - \\
\hline A4 & - & - & D6(13) & - \\
\hline A5 & - & - & D7(14) & - \\
\hline $5 V$ & VCC & $5 V$ & A,VDD(15,2) & - \\
\hline $3.3 V$ & - & - & - & - \\
\hline GND & GND & GND & K,VO,VSS,RW & GND \\
& & & $(16,3,1,5)$ & \\
\hline Cara & & & & \\
\hline
\end{tabular}

Cara kerja peralatan ini adalah sebagai berikut. Saat sensor ultrasonic mendeteksi jarak terhadap suatu benda, maka sensor akan mengirimkan data ke mikrokontroler Arduino Uno R3. Data yang diterima oleh mikrokontroler tersebut kemudian diolah untuk menjadi output, dimana layar LCD akan menampilkan output yang diterima dari mikrokontroler secara visual berbentuk tulisan (teks), sedangkan data yang sama turut diproses oleh Mp3 Player Shield yang mendekode data tersebut untuk menghasilkan output suara pada speaker dan buzzer. Melalui output visual pada layar LCD maupun output suara lewat speaker dan buzzer, maka pengendara mobil yang menggunakan sensor jarak ini dapat mengetahui jarak antara mobil dengan benda lain.

Rekaman suara yang digunakan untuk diputar oleh Mp3 Player Shield diperoleh dengan mengetik perintah yang diperlukan misalnya "sensor sudah aktif" di https://translate.google.com/ dalam pilihan Bahasa Indonesia. File audio dari website tersebut kemudian diunduh dalam format Mp3 dengan menggunakan software bernama Internet Download Manager. Proses Perekaman suara dapat dilihat ada gambar 4.

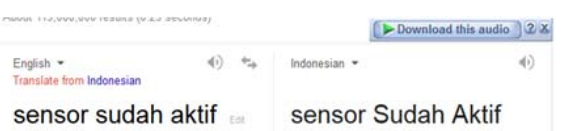

Gambar 4: Proses perekaman suara untuk Mp3 Player Shield

Setelah semua perintah selesai diunduh dalam bentuk Mp3, file-file tersebut kemudian disimpan ke Memory SD Card dengan kapasitas memori 4GB. Kartu memori tersebut kemudian dipasangkan ke Mp3 Player Shield agar suara yang sudah tersimpan dalam bentuk Mp3 dalam kartu memori dapat dipakai sebagai perintah oleh Mp3 Player Shield.Saat sensor dinyalakan maka Mp3 Player Shield yang akan mengeluarkan suara "sensor parkir menyala”. Kemudian dilanjutkan dengan "sensor sudah aktif” dan "silahkan mundur perlahan". Setelah kalimat-kalimat tersebut didengar oleh pengemudi maka pengemudi dapat memarkirkan mobil dan mobil dapat bergerak mundur secara perlahan. Saat mobil bergerak mundur maka Mp3 Player Shield akan memberitahukan jarak antara mobil yang diparkir dengan benda yang ada dibelakangnya misalnya "50 sentimeter" atau "40 sentimeter". Alat yang dirancang mampu mendeteksi jarak antara 2 sentimeter sampai dengan 200 sentimeter. Mp3 Player Shield telah diprogram agar mengeluarkan output audio yang memberitahukan pengemudi jarak antara mobil dengan penghalang, selama benda tersebut berada pada jangkauan yang dideteksi oleh sensor $(2-200 \mathrm{~cm})$. Saat jarak antara mobil dan penghalang mencapai $40 \mathrm{~cm}$ sampai $2 \mathrm{~cm}$ maka Mp3 Player Shield akan mengeluarkan audio yang menyuarakan “berhenti”. Pengaturan Mp3 Player Shield tersebut penting agar pengemudi mobil dapat berhati-hati dan menghentikan mobil, agar kendaraan tidak menabrak penghalang.

\section{B. Perancangan Software}

Perancangan software untuk penelitian ini menggunakan Altium Designer 16 dan Arduino.1.6.6. Altium Designer 16, yang digunakan untuk penggambaran skematik dan jalur PCB. Arduino.1.6.6 digunakan untuk membuat koding yang

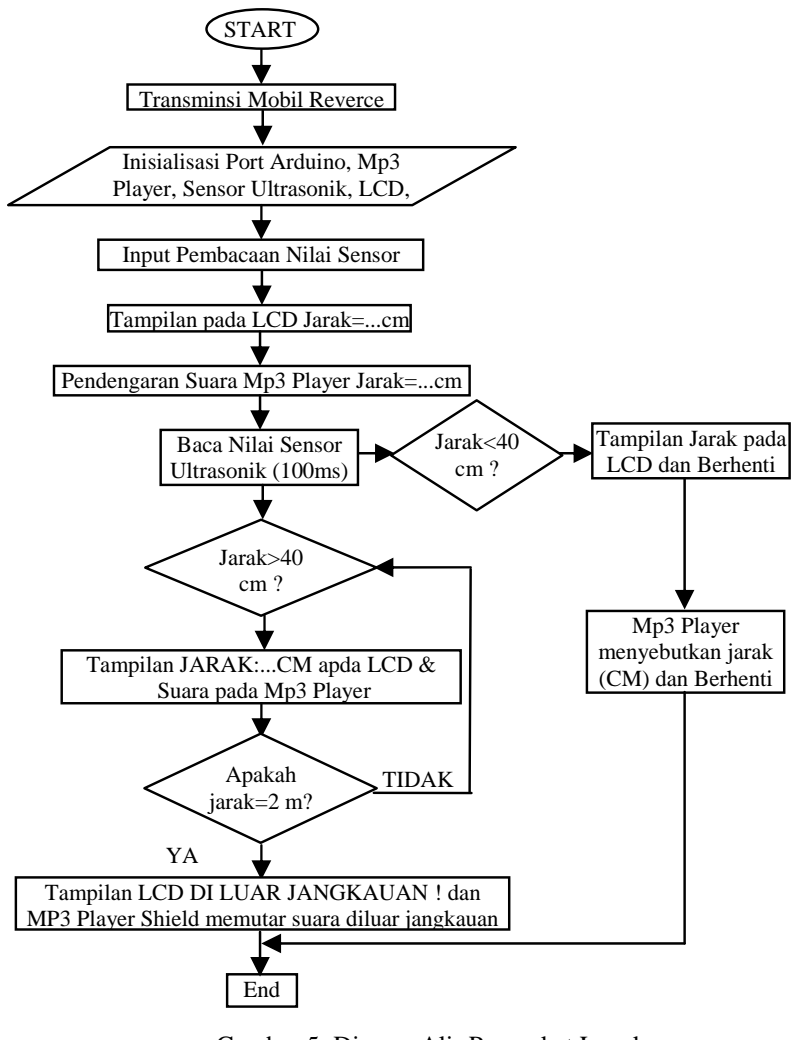

Gambar 5: Digram Alir Perangkat Lunak

diunggah ke dalam perangkat keras, agar alat yang dibangun dapat berfungsi sesuai keinginan peneliti. Adapun diagram alir perancangan perangkat lunak dapat dilihat pada gambar 5 .

\section{HASIL DAN PEMBAHASAN}

Hasil dan pembahasan rancang bangun sensor jarak sebagai alat bantu memarkir mobil berbasis mikrokontroler arduino uno adalah sebagai berikut.

C. Realisasi Hasil Perancangan 
Realisasi rancang bangun sensor jarak sebagai alat bantu memarkir mobil berbasis mikrokontroler arduino uno ditunjukkan pada Gambar 6 a dan b.

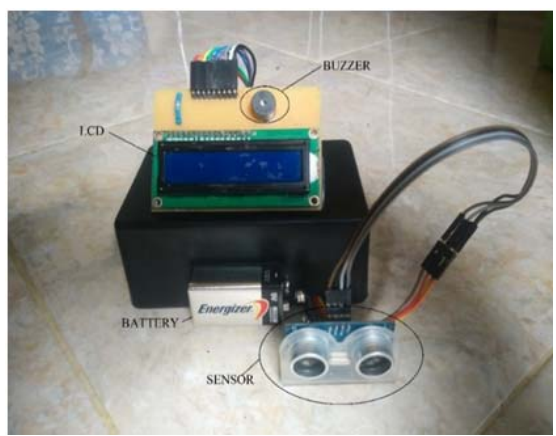

Gambar (a) Tampak luar

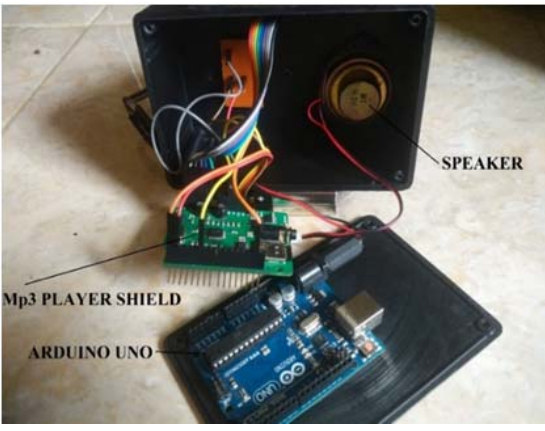

Gambar (b) Tampak dalam

D. Pengujian dan pembahasan sensor ultrasonik HC-SR04

Tujuan pengujian dari sensor ultrasonik HC-SR04 adalah untuk memastikan bahwa sensor ultrasonik yang digunakan dapat berfungsi untuk mengukur jarak dari lokasi sensor ke penghalang . Diagram blok pengujian sensor ultrasonik dapat dilihat pada Gambar 7.

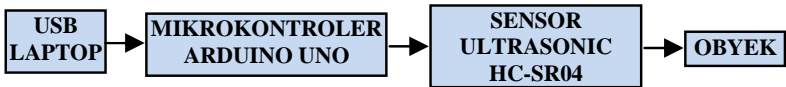

Gambar 7: Diagram blok pengujian sensor ultrasonik

Dari gambar 7 dapat dijelaskan bahwa dalam melakukan pengujian, sensor ultrasonik dihubungkan dengan mikrokontroler Arduino Uno yang didukung dengan sumber catu daya yang berasal dari laptop agar bisa mulai berfungsi. Peneliti memerlukan suatu objek yang akan dideteksi oleh sensor yang akan mengukur jarak antara objek dengan sensor. Dalam pengujian ini peneliti menggunakan tembok sebagai objek yang akan dideteksi jaraknya oleh sensor dan pita-ukur untuk pengukuran jarak. Hasil pengujian pembacaan sensor ultrasonik akan dilakukan dengan mengambil sampel jarak $30 \mathrm{~cm}, 60 \mathrm{~cm}, 100 \mathrm{~cm}$, dan $200 \mathrm{~cm}$. Hasil pengukuran ditunjukkan pada tabel 2 .

Pedro Paulo De J C Henriques: Rancang Bangun Sensor Jarak ......
TABEL II

HASIL PENGUJIAN PEMBACAAN SENSOR ULTRASONIK

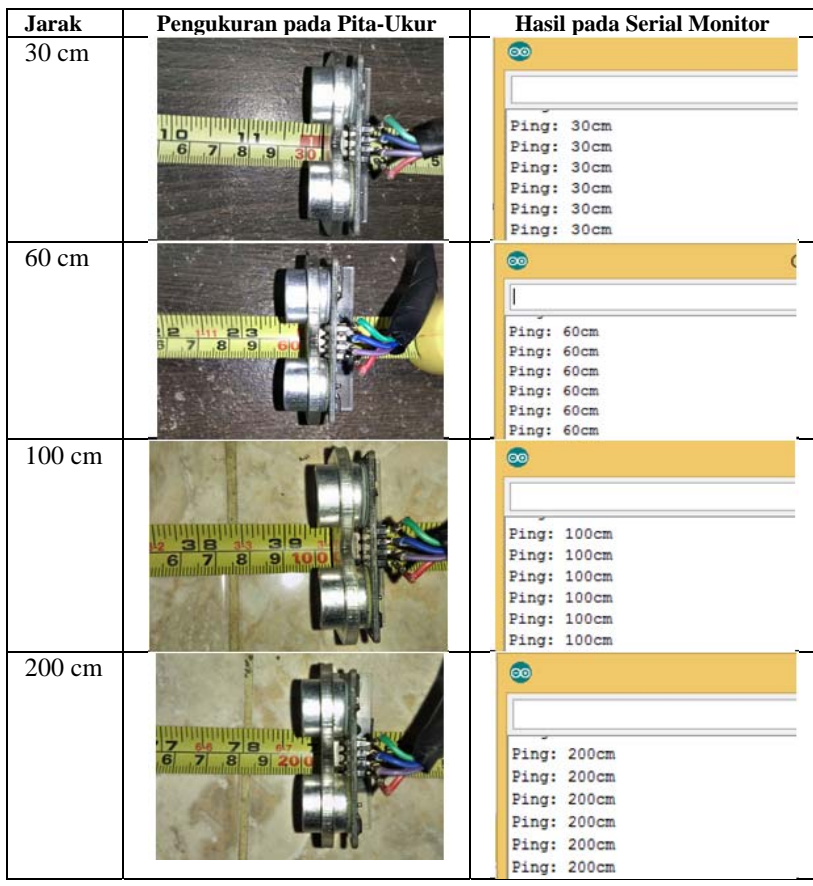

E. Pengujian dan Pembahasan Mp3 Shield Player, Speaker \& Buzzer

Pengujian Mp3 Shield Player bertujuan untuk memastikan bahwa Mp3 Shield Player telah berhasil menyimpan file-file audio yang akan digunakan kemudian dapat memainkan filefile audio tersebut sesuai dengan tujuan penelitian, dan memastikan bahwa speaker dan buzzer menghasilkan suara yang diinginkan. Diagram blok pengujian rangkaian MP3 Shield Player, speaker dan buzzer ditunjukkan pada gambar 8.

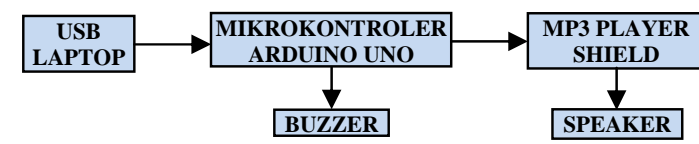

Gambar 8: Diagram Blok pengujian Mp3 Shield Player, Speaker \& Buzzer

Pengujian output suara pada buzzer dan speaker akan dilakukan dengan mengukur tegangan output pada pin buzzer melalui mikrokontroler arduino dan pin speaker pada Mp3 Player Shield, pengujian ini akan menggunakan alat multimeter digital.

1. Pengujian output suara pada buzzer

Pengujian output suara pada buzzer dapat dilihat pada gambar 9 .

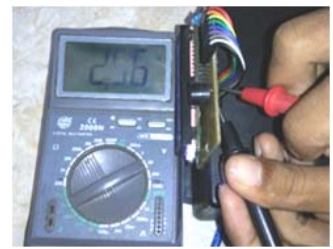

p-ISSN:1693 - 2951; e-ISSN: 2503-2372

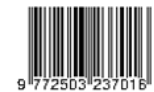


Gambar 9: Pengujian output suara buzzer

Gambar 9 adalah pengujian yang dilakukan pada rangkaian output buzzer melalui pin 5, pengujian dilakukan dengan cara Multimeter Digital pada range maksimal 20Volt. Dari hasil pengujian, output buzzer menghasilkan tegangan 2.56 VDC pada saat jarak antara sensor dan benda di bawah $40 \mathrm{~cm}$. Hasil ini menunjukkan bahwa buzzer mampu menghasilkan output suara yang diinginkan. Suara yang keluar adalah suara Beep yang panjang dalam waktu 1 detik.

\section{Pengujian output suara pada speaker}

Pengujian output suara pada speaker dapat dilihat pada gambar 10.

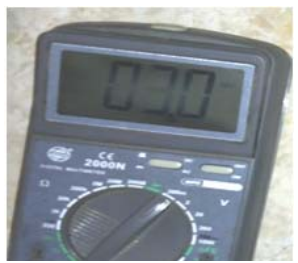

Gambar 10: Pengujian output suara pada speaker

Pengujian rangkaian output speaker dilakukan dengan cara mengatur Multimeter Digital pada range maksimal 200mVolt. Seperti yang terlihat pada Gambar 10, pengukuran tersebut menghasilkan tegangan $3 \mathrm{mV}$. Hasil tersebut menunjukkan bahwa speaker dapat menghasilkan suara sesuai yang diinginkan. Hasil pengukuran speaker bisa dilihat pada tabel 3 . TABEL III

HASIL PENGUJIAN OUTPUT SUARA PADA SPEAKER

\begin{tabular}{|c|c|c|c|}
\hline No & Jarak & Suara Mp3 Player Shield & Display LCD \\
\hline 1 & $40 \mathrm{CM}$ & $\begin{array}{c}\text { Empat Puluh Sentimeter } \\
\text { dan Berhenti }\end{array}$ & $\begin{array}{c}\text { BERHENTI !!! } \\
\text { PERLAHAN !!! }\end{array}$ \\
\hline 2 & $60 \mathrm{CM}$ & Enam Puluh Sentimeter & JARAK 60 CM \\
\hline 3 & $80 \mathrm{CM}$ & Delapan Puluh Sentimeter & JARAK 80 CM \\
\hline 4 & $120 \mathrm{CM}$ & $\begin{array}{c}\text { Seratus Dua Puluh } \\
\text { Sentimeter }\end{array}$ & $\begin{array}{c}\text { JARAK 120 } \\
\text { CM }\end{array}$ \\
\hline 5 & $140 \mathrm{CM}$ & $\begin{array}{c}\text { Seratus Empat Puluh } \\
\text { Sentimeter }\end{array}$ & $\begin{array}{c}\text { JARAK 140 } \\
\text { CM }\end{array}$ \\
\hline 6 & $160 \mathrm{CM}$ & $\begin{array}{c}\text { Seratus Enam Puluh } \\
\text { Sentimeter }\end{array}$ & $\begin{array}{c}\text { JARAK 160 } \\
\text { CM }\end{array}$ \\
\hline 7 & $180 \mathrm{CM}$ & $\begin{array}{c}\text { Seratus Delapan Puluh } \\
\text { Sentimeter }\end{array}$ & $\begin{array}{c}\text { JARAK 180 } \\
\text { CM }\end{array}$ \\
\hline 8 & $200 \mathrm{CM}$ & Dua Ratus Sentimeter & JARAK 200 \\
& & CM \\
\hline 9 & $>200 \mathrm{CM}$ & Di Luar Jangkauan & DI LUAR \\
& & & JANGKAUAN! \\
\hline
\end{tabular}

F. Pengujian dan pembahasan rangkaian output LCD

Rangkaian output LCD adalah rangkaian yang berfungsi untuk memberikan informasi visual kepada pengendara mobil untuk mengetahui jarak antara mobil dengan benda yang ada di belakang mobil. Diagram blok Pengujian rangkaian output LCD ditunjukkan pada Gambar 11.

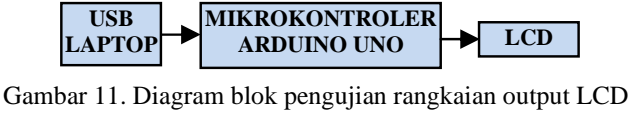

Dari Gambar 11 dapat dilihat bahwa mikrokontroler arduino uno mendapatkan tegangan input dari kabel usb laptop. LCD terkoneksi pada mikrokontroler arduino uno melalui pin analog dan mendapatkan tegangan $5 \mathrm{~V}$ dari pin mikrokontroler arduino uno. Pengujian rangkaian output LCD akan menggunakan sensor ultrasonik untuk membaca jarak pada obyek. Hasil pengujian rangkaian output LCD dapat dilihat pada Tabel 4 .

TABEL IV

HASIL PENGUJIAN RANGKAIAN OUTPUT LCD

\begin{tabular}{|c|c|c|}
\hline NO & Pengukuran Jarak (Cm) & Tampilan LCD \\
\hline 1 & $2 \mathrm{CM}$ & JARAK :2 LH \\
\hline 2 & $4 \mathrm{CM}$ & JARAK : 4 LH \\
\hline 3 & $100 \mathrm{CM}$ & JARRK :160 CH \\
\hline 4 & $120 \mathrm{CM}$ & JARAK : $120 \mathrm{CH}$ \\
\hline 4 & $150 \mathrm{CM}$ & JARAK : 150 CH \\
\hline 5 & $200 \mathrm{CM}$ & JARAK $1260 \mathrm{CH}$ \\
\hline
\end{tabular}

G. Pengujian dan pembahasan keseluruhan alat

Pengujian perangkat keras secara keseluruhan dilakukan setelah pengujian tiap blok dilakukan dan semua blok sudah berfungsi sesuai dengan yang direncanakan kemudian blokblok tersebut disatukan menjadi sebuah sistem.

Untuk melakukan pengujian terhadap perangkat keras secara keseluruhan diperlukan beberapa tahap sebagai berikut:

1. Sensor Ultrasonik HC-SR04, Mp3 Player Shield, speaker, buzzer dan LCD sudah dihubungkan dengan mikrokontroler Arduino Uno.

2. Meghubungkan dan menghidupkan catu daya dengan mikrokontroler Arduino Uno.

3. Menaruh objek di depan Prototipe.

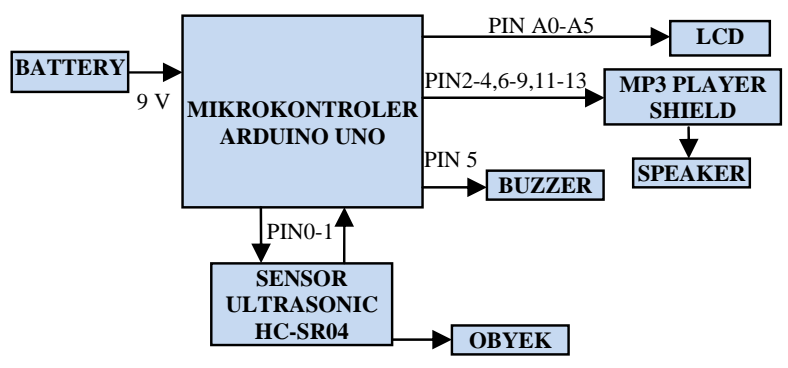

Gambar 12: Diagram blok pengujian dan pembahasan keseluhan alat

4. Amati jarak antara sensor dengan objek dan bandingkan hasil yang diperoleh pada sensor jarak di LCD dan suara pada Mp3 Palyer Shield.

Gambar 12 adalah diagram blok pengujian dan pembahasan keseluruhan sensor jarak sebagai alat bantu memarkir mobil. Pengujian dan pembahasan keseluruhan alat merupakan penggabungan perangkat keras dan perangkat lunak yang sudah dibahas. adapun prototipe yang sudah dibuat untuk menguji alat ini, gambar prototipe ditunjukkan pada gambar 13 (a) dan (b). 


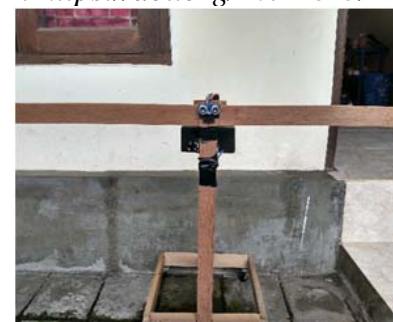

(a)

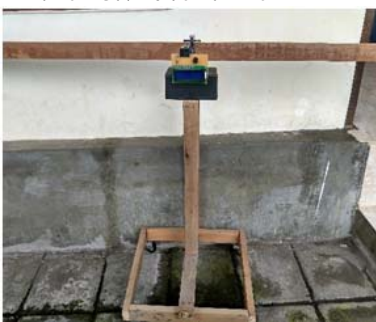

(b)

Gambar 13: Prototipe Alat

Untuk mencoba alat sensor jarak yang dirancang dalam penelitian ini, penulis membuat sebuah alat bantu yang berperan sebagai prototipe bagian belakang mobil dengan panjang $129 \mathrm{~cm}$ dan tinggi $59 \mathrm{~cm}$ sebagai ukuran bamper belakang mobil Suzuki Karimun Wagon R. Prototipe ini terbuat dari batang-batang kayu yang dipasang seperti Gambar 13. Sensor akan dipasang di tengah pada bagian atas protipe dan LCD pada bagian bawah prototipe. Batang kayu panjang pada prototipe tersebut merepresentasikan bamper mobil atau bagian belakang mobil, sedangkan roda yang dipasang dibagian bawah prototipe membantu menggerakan prototipe maju dan mundur, sebagaimana mobil bergerak maju dan mundur. LCD dipasang pada batang kayu agar memudahkan pembacaan jarak yang ditampilkan pada LCD saat menggunakan prototipe. Apabila diaplikasikan pada mobil secara nyata, LCD idealnya akan diletakkan pada dashboard di bagian depan pengemudi bersama speaker dan buzzer. Akan tetapi untuk penelitian ini, peneliti menggunakan prototipe dengan skala kecil agar memudahkan penelitian dan menggunakan waktu dan biaya secara efisien.

Pengujian keseluruhan sensor jarak sebagai alat bantu memarkir mobil berbasis mikrokontroler Arduino Uno akan dilakukan di area parkir mobil yang berada di Jalan Tukad Badung XIII A nomor 4, Denpasar Selatan.

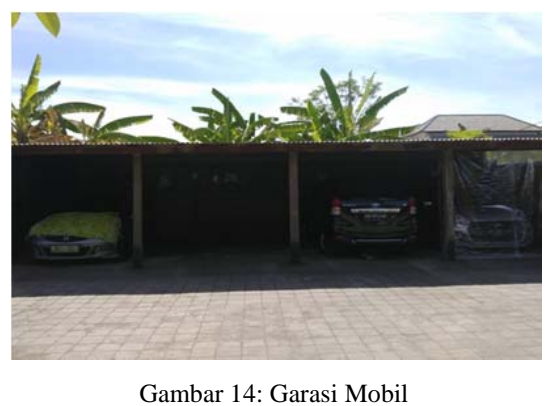

Gambar 14 merupakan tempat yang akan peneliti gunakan untuk melakukan pengujian dan pembahasan perangkat keras. Pengukuran sensor jarak bamper mobil dengan tembok dimulai pada jarak $200 \mathrm{~cm}$ dan semakin berkurang saat sensor jarak bergerak semakin mendekati tembok. Alat dinyalakan pertama kali dan alat menghasilkan output visual melalui LCD dan suara lewat speaker yang tertulis dan bersuara "SENSOR PARKIR MENYALA" dilanjutkan dengan "SENSOR SUDAH AKTIF" dan dilanjutkan dengan "SILAKAN MUNDUR PERLAHAN”. Untuk hasil ditunjukkan pada Gambar 15 a, b, dan c.

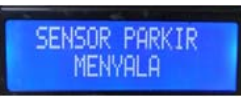

(a)

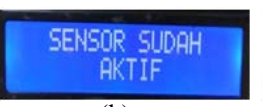

(b)
Gambar 15: Tampilan sensor pertama kali di nyalakan

Setelah melihat dan mendengarkan suara tersebut pengemudi akan mundur untuk memarkir mobil, berikut ini adalah pengukuran jarak bamper mobil dengan tembok :

\section{Pengujian prototipe pada jarak di atas 200 sentimeter}

Saat jarak antara bamper mobil dengan tembok di atas 200 cm maka prototipe akan menghasilkan output visual melalui LCD dan suara lewat speaker yang tertulis dan bersuara "DI LUAR JANGKAUAN !”. Seperti yang ditunjukkan pada Gambar 16.

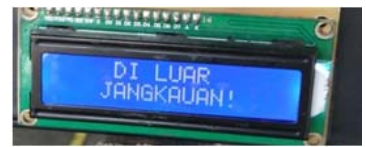

Gambar 16: Tampilan di luar jangkauan LCD dan Suara

\section{Pengujian prototipe pada jarak 200 Sentimeter}

Pengujian dilakukan dengan prototipe didorong mundur dan sensor berhadapan dengan tembok sejauh $200 \mathrm{~cm}$ pada pita-ukur seperti yang ditunjukkan pada Gambar 17.

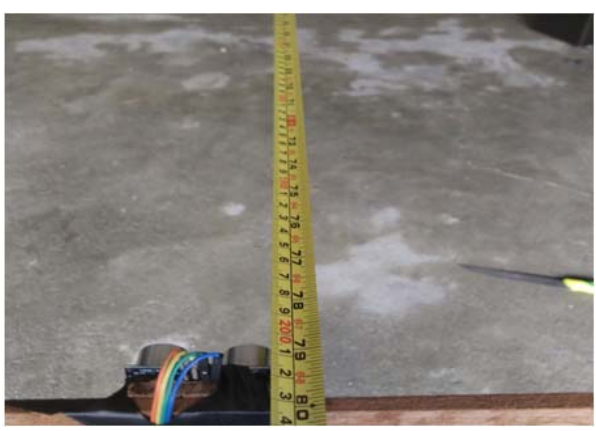

Gambar 17: Jarak 200cm pada pita-ukur

Selanjutnya cek tampilan output LCD dan output suara pada Mp3 Player Shield ditunjukkan pada Gambar 4.23.

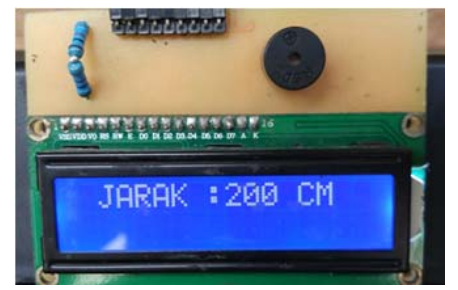

Gambar 18: Tampilan jarak pada LCD $200 \mathrm{~cm}$

Gambar 18 adalah hasil output visual LCD dan output suara, output visual melalui LCD "JARAK : 200 CM" dan speaker akan bersuara "DUA RATUS SENTIMETER".

\section{Pengujian prototipe pada jarak 150 Sentimeter}

Pengujian dilakukan dengan prototipe didorong mundur atau dikurangi jarak menjadi $150 \mathrm{~cm}$ pada pita-ukur, dapat dilihat pada Gambar 19. 


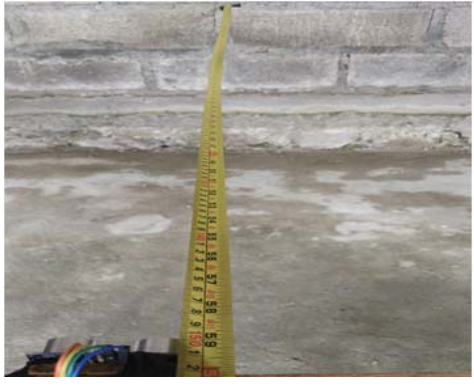

Gambar 19: Jarak 150 CM pada pita-ukur

Hasil Pengecekan tampilan output LCD dan output suara pada Mp3 Player Shield dapat dilihat pada gambar 20.

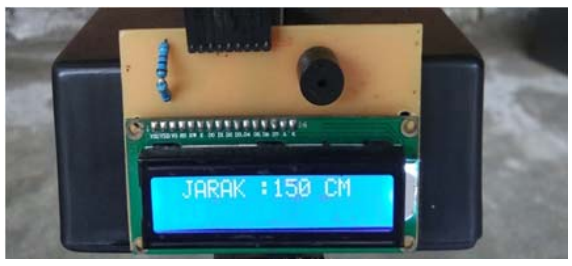

Gambar 20: Tampilan jarak pada LCD 150 CM

Gambar 20 adalah hasil output visual LCD dan output suara, output visual melalui LCD “JARAK : 150 CM" dan speaker akan bersuara "SERATUS LIMA PULUH SENTIMETER”.

4. Pengujian prototipe pada jarak 100 Sentimeter

Pengujian dilakukan dengan prototipe didorong mundur atau dikurangi jarak menjadi $150 \mathrm{~cm}$ pada pita-ukur, ditunjukkan pada Gambar 21.

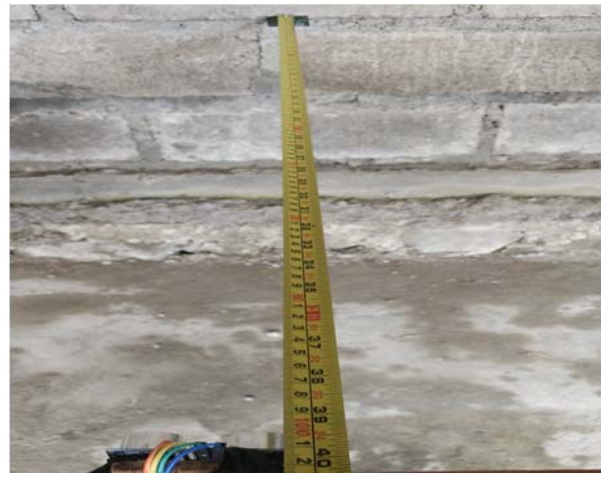

Gambar 21: Jarak 100 CM pada pita-ukur

Hasil pengecekan tampilan output LCD dan output suara pada Mp3 Player Shield ditunjukkan pada Gambar 22.

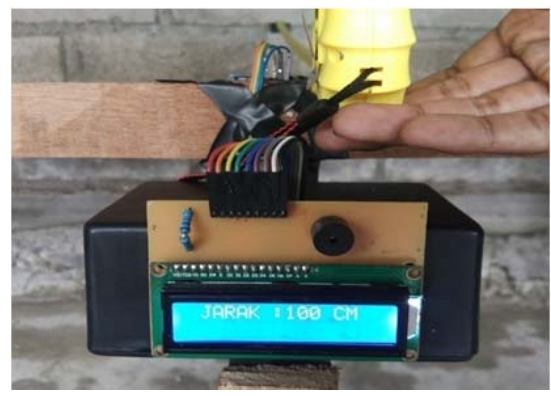

Gambar 22: Tampilan jarak pada LCD 100 CM
Gambar 22 adalah hasil output visual LCD dan output suara, output visual melalui LCD "JARAK : 100 CM" dan speaker akan bersuara "SERATTUS SENTIMETER”.

5. Pengujian prototipe pada jarak 40 Sentimeter

Pengujian dilakukan dengan prototipe didorong mundur atau dikurangi jarak menjadi $40 \mathrm{~cm}$ pada pita-ukur, seperti yang ditunjukkan pada Gambar 23.

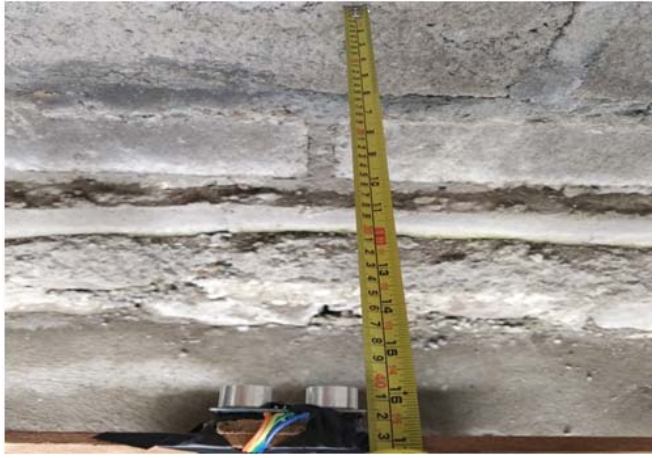

Gambar 23: Jarak 40 CM pada pita-ukur

Hasil pengecekan tampilan output LCD dan output suara pada Mp3 Player Shield ditunjukkan pada Gambar 24.

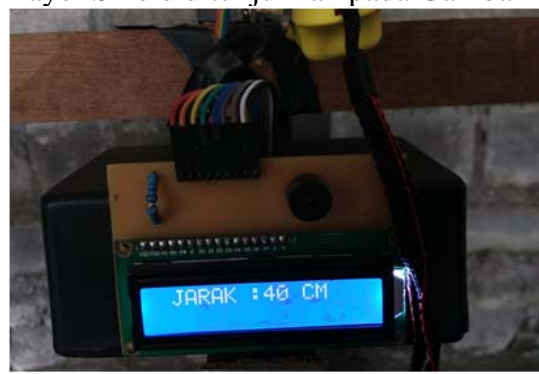

Gambar 24: Tampilan jarak pada LCD 40 CM

Gambar 24 adalah hasil output visual LCD dan output suara, output visual melalui LCD "JARAK : 40 CM" dan speaker akan bersuara "EMPAT PULUH SENTIMETER". Setelah jarak disebutkan melalui LCD dan suara selanjutnya output visual LCD menampilkan "BERHENTI !!!” dan speaker akan bersuara "BERHENTI" dilanjutkan dengan Buzzer berbunyi beep yang panjang. Jarak $40 \mathrm{~cm}$ adalah batas jarak yang ditetapkan peneliti dimana alat akan mulai memperingatkan pengendara mobil untuk berhenti demi menghindari tabrakan. Hasil ditunjukkan pada Gambar 25.

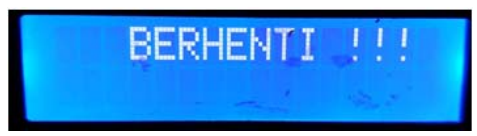

Gambar 25: Tampilan berhenti pada LCD

6. Pengujian prototipe pada jarak 20 Sentimeter

Pengujian dilakukan dengan prototipe didorong mundur atau dikurangi jarak menjadi $20 \mathrm{~cm}$ pada pita-ukur, dapat dilihat pada Gambar 26. 


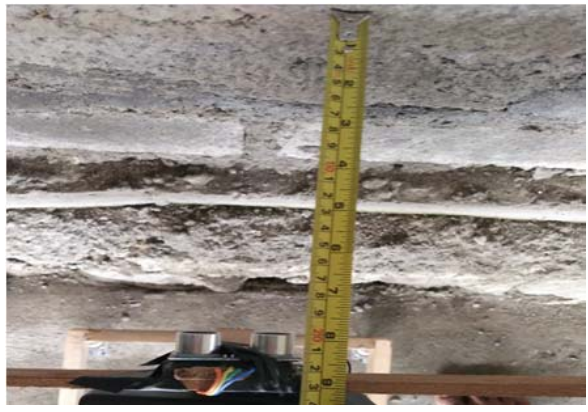

Gambar 26: Jarak 20 CM pada pita-ukur Hasil pengecekan tampilan output LCD dan output suara pada Mp3 Player Shield ditunjukkan pada Gambar 27.

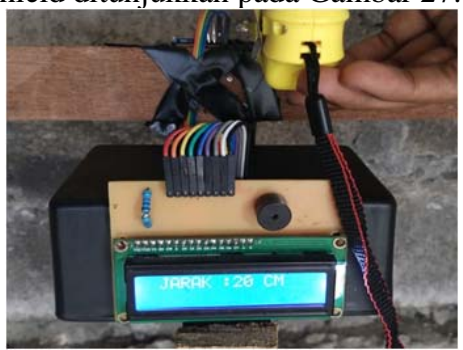

Gambar 27: Tampilan jarak pada LCD 20 CM

Gambar 27 adalah hasil output visual LCD dan output suara, output visual melalui LCD "JARAK : 20 CM" dan speaker akan bersuara "DUA PULUH SENTIMETER". Setelah jarak disebutkan melalui LCD dan suara selanjutnya output visual LCD menampilkan "BERHENTI !!!", speaker akan bersuara "BERHENTI” dan Buzzer akan berbunyi beep yang panjang. Jarak $20 \mathrm{~cm}$ adalah jarak di bawah $40 \mathrm{~cm}$ dan alat telah diatur agar saat jarak sensor dengan benda lain sama dengan atau di bawah $40 \mathrm{~cm}$ maka alat akan memperingati pengendara untuk berhenti untuk mecegah tabrakan. Hasil ditunjukkan pada Gambar 28.

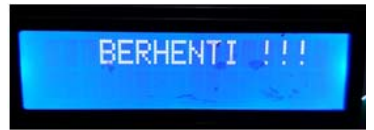

Gambar 28: Tampilan berhenti pada LCD

Jika prototipe terus dimundurkan secara terus-menerus maka jarak akan tetap ditampilakan pada LCD dan suara yang dihasilkan Mp3 Player Shield, kemudian LCD menampilkan “BERHENTI !!!” speaker akan bersuara "BERHENTI” saat jarak mencapai 2cm dan Buzzer berbunyi beep yang panjang, sampai jarak antara prototipe dan benda lain mencapai $2 \mathrm{~cm}$. Saat prototipe mencapai jarak di bawah $2 \mathrm{~cm}$ maka tampilan LCD dan suara yang dihasilkan akan sama seperti jarak $200 \mathrm{~cm}$, tertulis dan menyuarakan "DI LUAR JANGKAUAN !" seperti yang ditunjukkan pada Gambar 16.

\section{KESIMPULAN}

Kesimpulan dari penelitian sensor jarak sebagai alat bantu memarkir mobil berbasis mikrokontroler arduino uno ini adalah dari sebagai berikut :
1. Jarak yang dibaca oleh sensor ultrasonik HC-SR04 sudah sama dengan jarak yang ditampilkan pada LCD dan Sama juga dengan suara yang dihasilkan Mp3 Player Shield;

2. Alat ini bisa membatu parkir mobil dengan jarak minimal 2 sentimeter dan maksimal 200 sentimeter.

\section{REFERENSI}

[1] Yenni, H., Patria A. Rekayasa Parking Assitance System Kendaraan dengan Sensor Ultrasonik. Teknik Informatika, STMIK Amik-Riau, 2015.

[2] Wong, D. K. A Sensitive DIY Ultrasonic Range Sensor. http:// www.kerrywong.com/2011/01/22/a-sensitive-diy-ultrasonic-rangesensor/, 2011.

[2] Robotic - ID. Cara Kerja Sensor Ultrasonic. http://www .robotic-id. Org /2015/10/cara-kerja-sensor-ultrasonik.html. 2016.

[3] Arduino. What is Arduino?. www.arduino.cc/en/Guide/Introduction, 2016

[4] Sarunggalo K.S.2017. Rancang Bangun Alat Ukur Uji Emisi Gas Karbon Monoksida(CO) Berbasis Mikrokontroler. Denpasar: Universitas Udayana; 2017.

[5] Sparkfun. MP3 Player Shield Hookup.www .learn. sparkfun. Com / tutorials /mp3-player-shield-hookup, 2013.

[6] Sang Penagajar. Mengenal Speaker dan Cara Kerjanya. http://www. sangpengajar.com/2015/07/mengenal-speaker-dan-cara-kerjanya.html, . 2015

[7] Shallowsky. Arduino: Piezzo Speakers (Buzzers). http://shallowsky .com / arduino/class/buzzer.jpg. 2016

[8] Suprianto. Liquid crystal Display (LCD) 16x2. http://blog. unnes. ac. id/ antosupri /liguid-crystal-display-lcd-16-x-2 